\title{
10.6\% Certified Colloidal Quantum Dot Solar Cells via Solvent-Polarity-Engineered Halide Passivation
}

\author{
Xinzheng Lan, Oleksandr Voznyy, F. Pelayo García de Arquer, Mengxia Liu, Jixian Xu, Andrew \\ H. Proppe, Grant Walters, Fengjia Fan, Hairen Tan, Min Liu, Zhenyu Yang, Sjoerd Hoogland, \\ Edward H. Sargent* \\ Department of Electrical and Computer Engineering, University of Toronto, 10 \\ King's College Road, Toronto, Ontario, M5S 3G4, Canada
}

\section{Supporting Information - Experimental details}

CQD synthesis and MAI-treatment of PbS CQDs. PbS CQDs were synthesized following our previous reports. ${ }^{1}$ The resultant oleate-capped $\mathrm{PbS}$ CQDs were finally dispersed in toluene with a concentration of ca. $100 \mathrm{mg} / \mathrm{mL}$. For a typical MAI treatment process, $1.5 \mathrm{~mL}$ toluene-DMF (2:1 vol\%) dispersed MAI $\left(40 \times 10^{-3} \mathrm{M}\right)$ solution was added to $2 \mathrm{~mL} \mathrm{PbS} \mathrm{CQDs} \mathrm{in} \mathrm{a} \mathrm{vial} \mathrm{slowly} \mathrm{(1}$ drop per $10 \mathrm{~s}$ ). Gentle shaking, instead of strong stirring was applied to faciliate the formation of homogeneous solution. Note that too fast injection of MAI solution resulted in irreversible precipitation of CQDs. The CQDs solution was kept in the glovebox for $12 \mathrm{~h}$. Methanol was employed to precipitate the CQDs. Following fully drying, the nanocrystals were dispersed in octane with a concentration of $50 \mathrm{mg} / \mathrm{mL}$. The treatment process for our $\mathrm{I}_{2}$ recipe followed our previous report.

ZnO nanoparticle synthesis and film deposition. The synthesis of $\mathrm{ZnO}$ nanoparticles is based on the methods reported in our previous work. ${ }^{2}$ After two-time washing with methanol, the nanoparticles were dissoloved in a mixture of chloroform and methanol to facilitate subsequent film formation. For the preparation of $\mathrm{ZnO}$ film, the $\mathrm{ZnO}$ nanocrystal solution was spin-cast on patterned ITO glass at 6,000 rpm for $10 \mathrm{~s}$. A second $\mathrm{ZnO}$ spincasting was applied to complete the $\mathrm{ZnO}$ layer.

\section{Material characterization:}

SEM was obtained on a Hitachi S-8200 scanning electron microscope. HRTEM samples were prepared by adding a drop of the solution of CQDs onto an ultrathin-carbon film on lacey-carbon support film (Ted Pella 01824) and subsequently imaged using Hitachi HF3300 operating at 300 $\mathrm{kV}$.

Optical absorption measurements were carried out in a Lambda 950500 UV-Vis-IR spectrophotometer. Photoluminescence measurements were done with a Horiba Fluorolog Time Correlated Single Photon Counting system equipped with UV/VIS/NIR photomultiplier tube detectors, dual grating spectrometers, and a monochromatized xenon lamp excitation source. Absolute PLQY measurements were done inside a Quanta-Phi integrating sphere. 
XPS measurements were performed on Thermo Scientific K-Alpha system with Al Ka source. Thin films were prepared on ITO substrates and electron flood gun was used for charge compensation to avoid peak shifting. A $50 \mathrm{eV}$ pass energy and $0.05 \mathrm{eV}$ scan step was used to obtain high-resolution spectra. The atomic ratios are obtained by integrating the area under the peaks and scaling by atomic sensitivity factors. Nevertheless, the degree of screening of the surface vs. core of the QDs is different and cannot provide a reliable estimate of the surface coverage by ligands. We thus normalize the iodide numbers by the amount of oleic acid in the untreated QDs.

Device fabrication. $\mathrm{PbS} \mathrm{QDs}$ were deposited following a typical layer-by-layer spin-casting process. A 0.22 um filter was used for the deposition of PbS QDs. For each TBAI layer, 2 drops of $\mathrm{PbS}$ CQDs in octane $(50 \mathrm{mg} / \mathrm{mL})$ were deposited onto the $\mathrm{ZnO}$ substrates and were spincasted at $2500 \mathrm{rpm}$ for $10 \mathrm{~s}$. The film was then soaked in TBAI $(5 \mathrm{mg} / \mathrm{mL})$ containing methanol solution and spun after $30 \mathrm{~s}$ at the same speed for $10 \mathrm{~s}$. This was followed by a two-time methanol rinse process. The process was repeated 9-10 times to achieve the desired thickness of the active layer. Following the TBAI stack of layers, two layers of EDT-exchanged PbS QDs were deposited. In a typical process, $\mathrm{PbS}$ was deposited with the same procedure as applied for the TBAI layers. A $0.01 \%$ v:v EDT:acetonitrile solution was deposited on the film and spun after 30 s soaking, which was followed by a 3-time acetonitrile rinsing process. For the top electrode, $120 \mathrm{~nm} \mathrm{Au}$ was deposited on the PbS film to complete the device.

\section{Device characterization}

J-V and EQE characterization: Current-voltage traces were acquired with a Keithley 2400 source measuring unit under simulated AM1.5G illumination (Sciencetech class A). Devices were measured under a continuous flow of nitrogen gas. External-quantum-efficiency spectra were taken by subjecting the cells to monochromatic illumination (400 W Xe lamp passing through a monochromator and appropriate cut-off filters). The output power was measured with Newport 818-UV and Newport 838-IR photodetectors. The beam was chopped at $220 \mathrm{~Hz}$ and focused in the pixel together with a solar-simulator at 1 sun intensity to provide for light bias. The response of the cell was acquired with a Lakeshore pre-amplifier connected to Stanford Research 830 lock-in amplifier at short-circuit conditions.

\section{References}

(1) Ip, A. H.; Thon, S. M.; Hoogland, S.; Voznyy, O.; Zhitomirsky, D.; Debnath, R.; Levina, L.;

Rollny, L. R.; Carey, G. H.; Fischer, A.; Kemp, K. W.; Kramer, I. J.; Ning, Z.; Labelle, A. J.;

Chou, K. W.; Amassian, A.; Sargent, E. H. Nat. Nano. 2012, 7, 577.

(2) Lan, X.; Voznyy, O.; Kiani, A.; García de Arquer, F. P.; Abbas, A. S.; Kim, G.-H.; Liu, M.;

Yang, Z.; Walters, G.; Xu, J.; Yuan, M.; Ning, Z.; Fan, F.; Kanjanaboos, P.; Kramer, I.;

Zhitomirsky, D.; Lee, P.; Perelgut, A.; Hoogland, S.; Sargent, E. H. Adv. Mater. 2016, 28, 299. 


\section{Supporting Information - Figures}

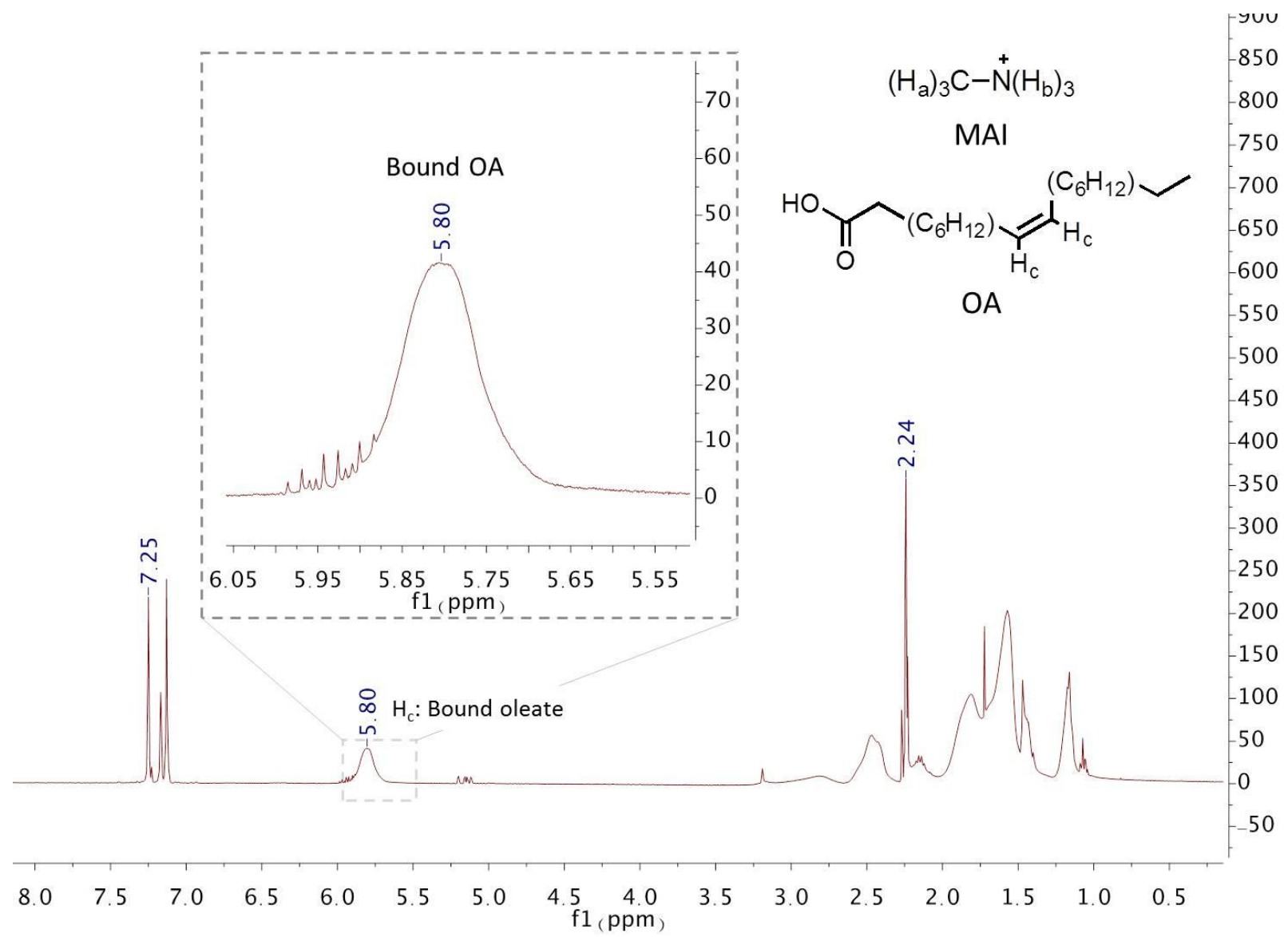

Figure S1 ${ }^{1} \mathrm{H}$ NMR spectrum of untreated OA-capped PbS CQDs. 
10.6\% Certified Colloidal Quantum Dot Solar Cells via Solvent-Polarity-Engineered Halide Passivation Nano Letters

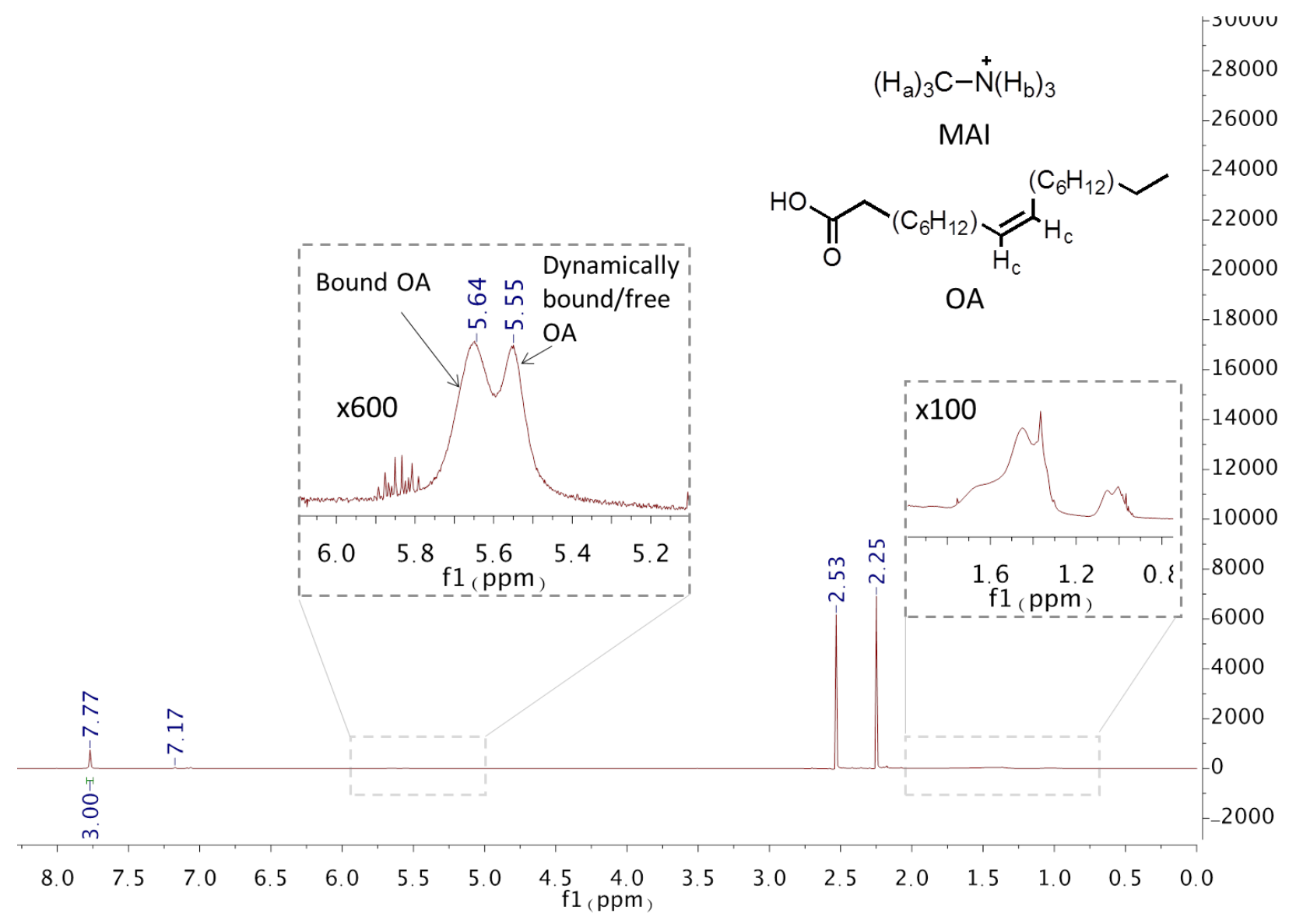

Figure S2 ${ }^{1} \mathrm{H}$ NMR spectrum of OA-capped PbS CQDs following MAI treatment without methanol wash. 
10.6\% Certified Colloidal Quantum Dot Solar Cells via Solvent-Polarity-Engineered Halide Passivation Nano Letters

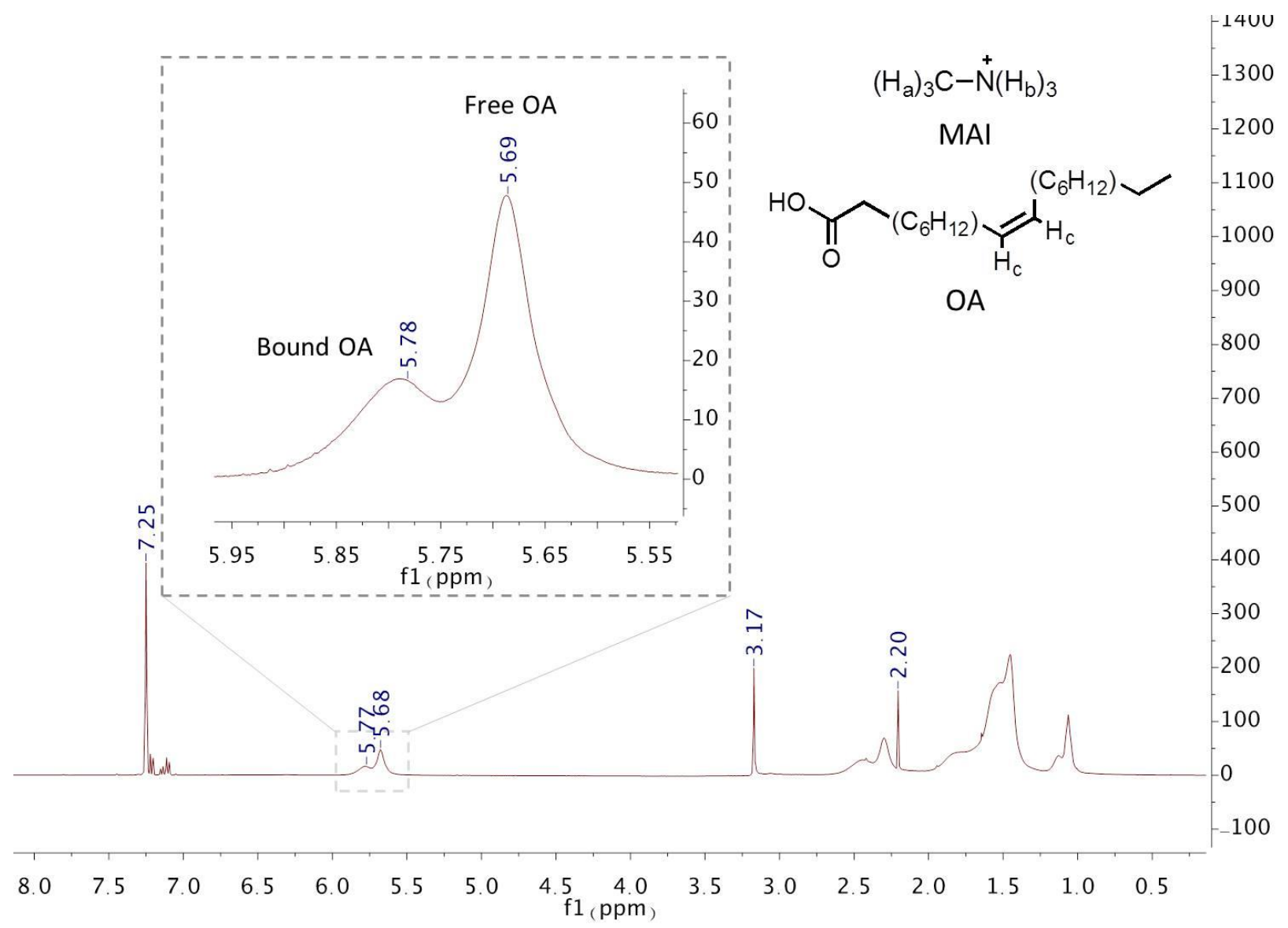

Figure S3 ${ }^{1} \mathrm{H}$ NMR spectrum of untreated OA-capped PbS CQDs in the presence of free OA. 
10.6\% Certified Colloidal Quantum Dot Solar Cells via Solvent-Polarity-Engineered Halide Passivation Nano Letters

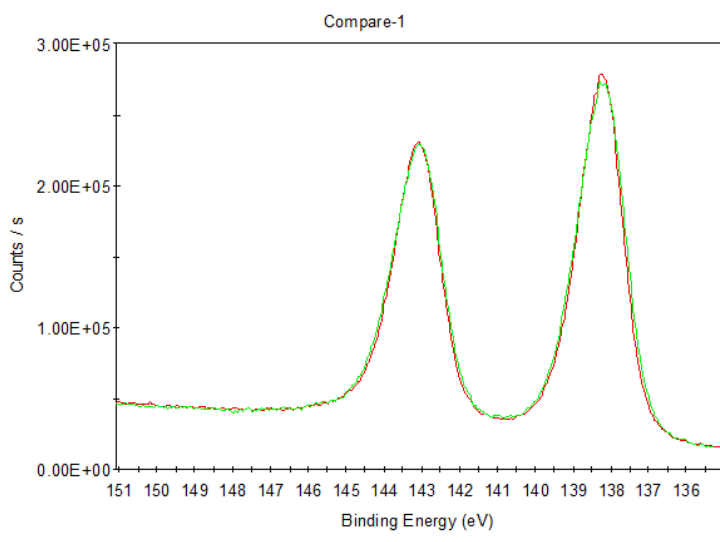

a)

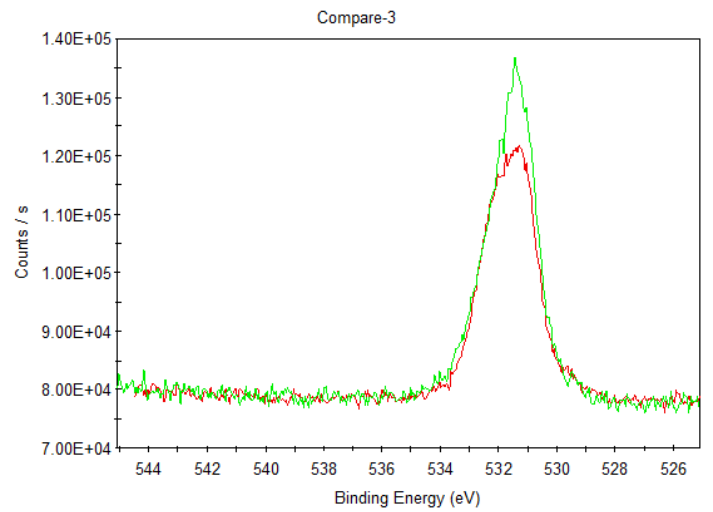

c)

Figure S4 XPS measurements. (a) Spectra before and after MAI treatment are normalized to $\mathrm{Pb}$ amount, (b) decrease of carbon amount after MAI solution exchange and one washing step, (c) decrease of carboxylate oxygen amount after MAI solution exchange and one washing step, (d) absence of ammonium signal in the final films treated with TBAI (the rise at higher binding energies is due to $\mathrm{Pb} 4 \mathrm{~d}$ peak).
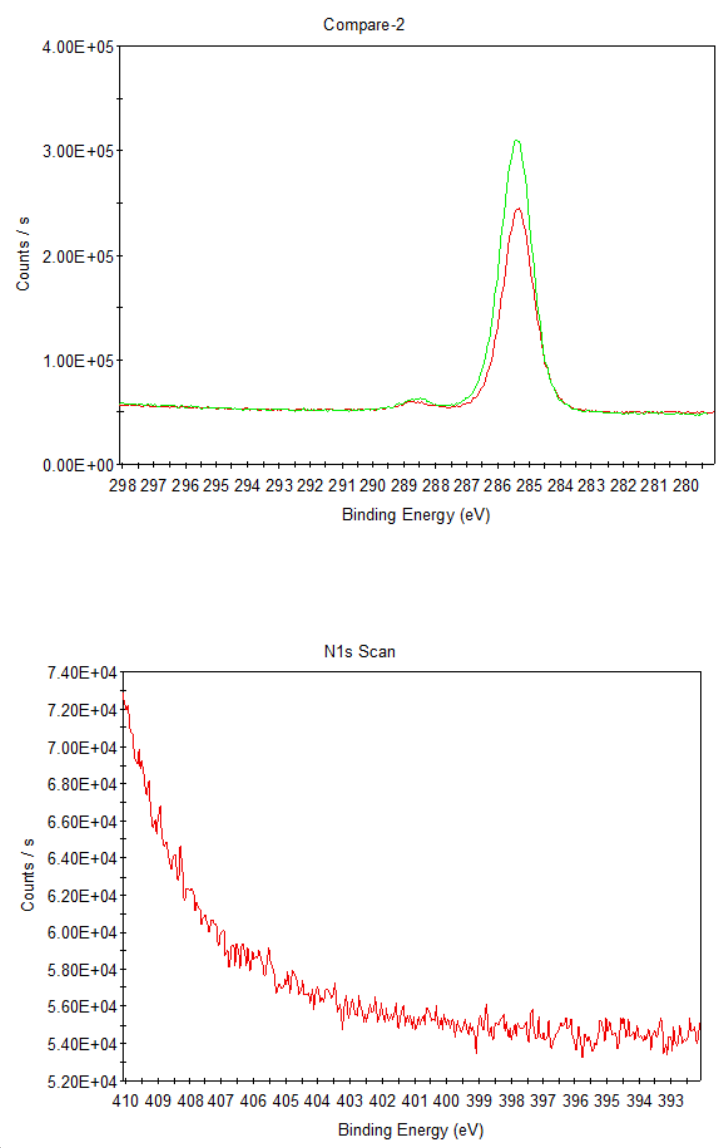

d) 
10.6\% Certified Colloidal Quantum Dot Solar Cells via Solvent-Polarity-Engineered Halide Passivation Nano Letters

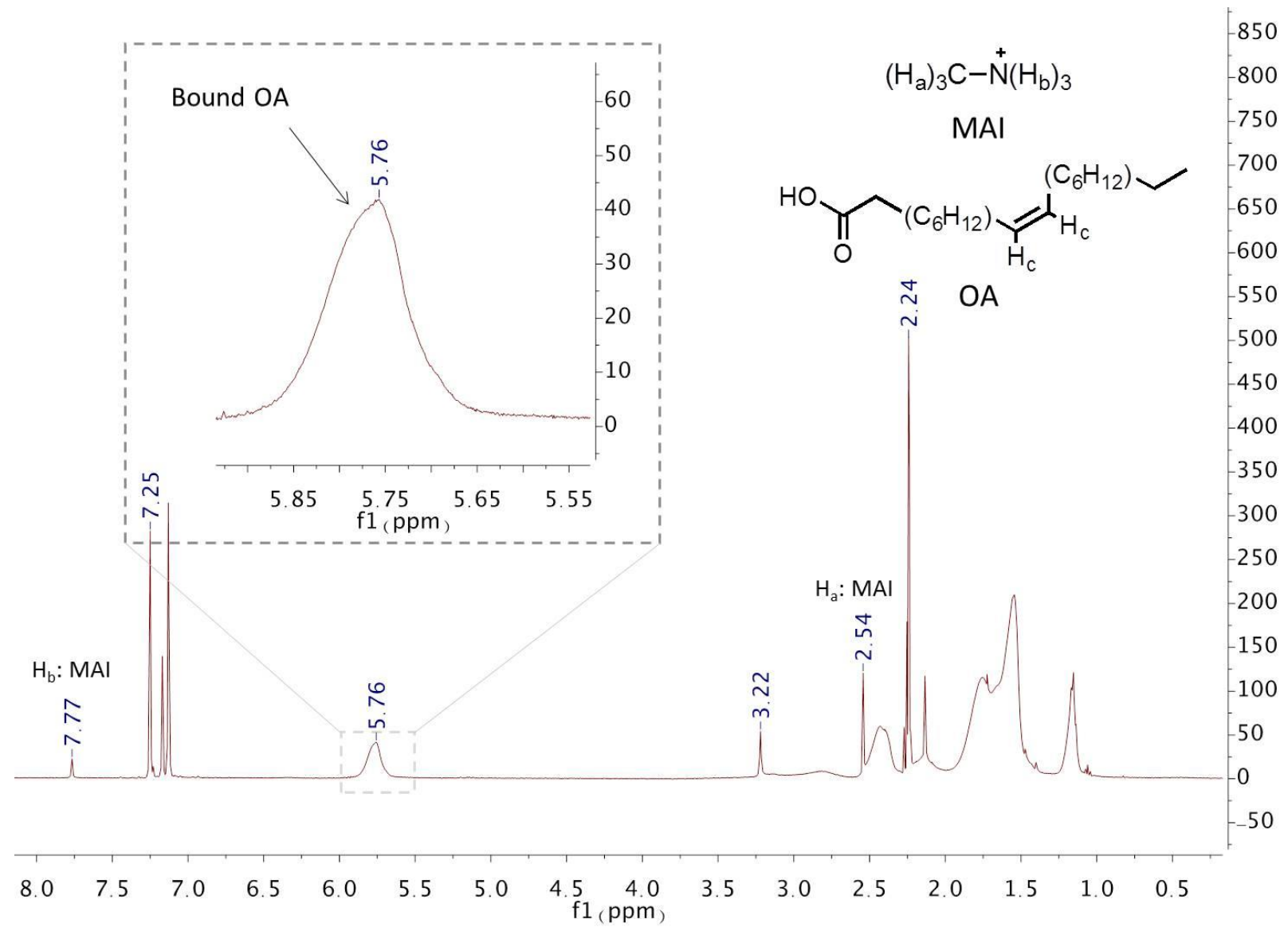

Figure S5 ${ }^{1} \mathrm{H}$ NMR spectrum of OA-capped PbS CQDs following MAI treatment and methanol washing 


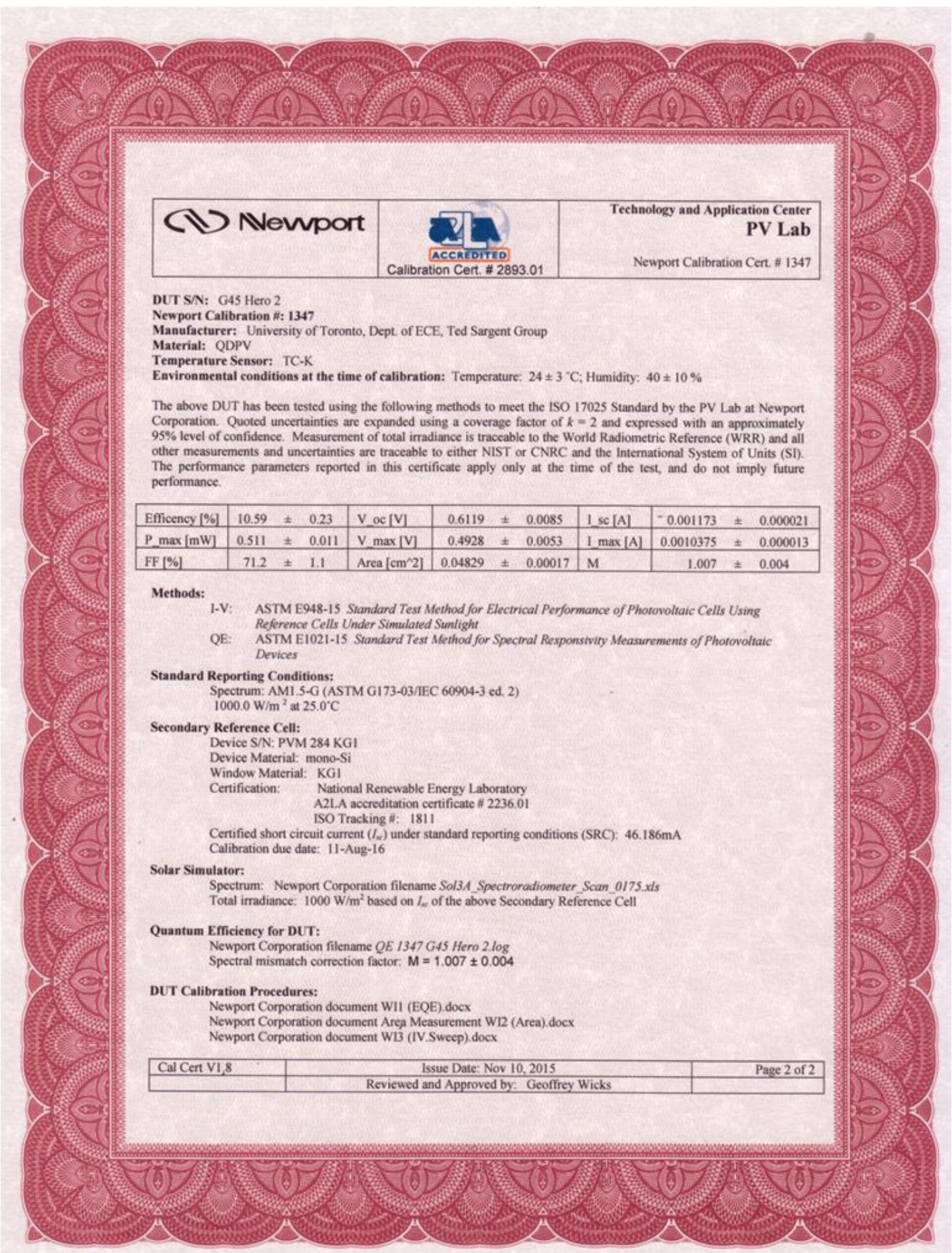

Figure S6 Figures of merits for a certified MAI-treated PbS CQD device as measured by an accredited PV calibration laboratory (Newport Technology and Application Center - PV Lab). 
10.6\% Certified Colloidal Quantum Dot Solar Cells via Solvent-Polarity-Engineered Halide Passivation Nano Letters
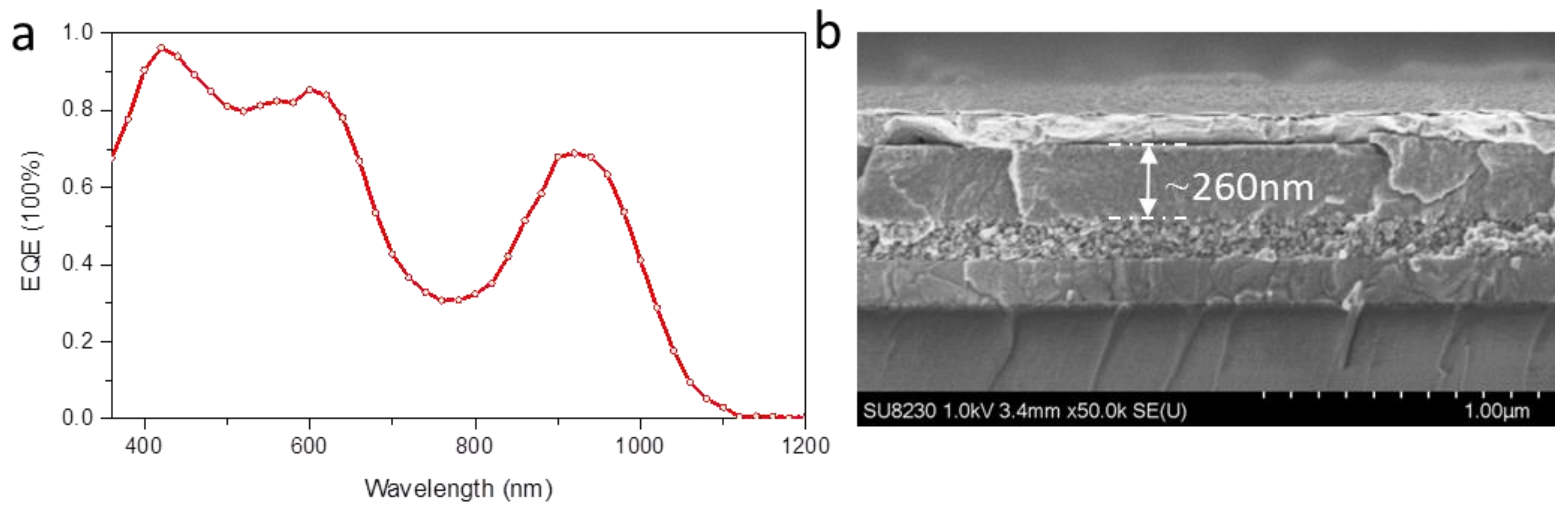

Figure S7 External quantum efficiency (a) and cross-sectional SEM image (b) of a 260 nm-thick device. 